\title{
Microwave-assisted synthesis of calcium phosphate nanowhiskers
}

\author{
Sahil Jalota, A. Cuneyt Tas, ${ }^{\text {a) }}$ and Sarit B. Bhaduri \\ School of Materials Science and Engineering, Clemson University, Clemson, South Carolina 29634
}

(Received 12 February 2004; accepted 29 March 2004)

Calcium phosphate [single-phase hydroxyapatite (HA), single-phase tricalcium phosphate (TCP), and biphasic HA-TCP] nanowhiskers and/or powders were produced by using a novel microwave-assisted "combustion synthesis (auto ignition)/molten salt synthesis" hybrid route. This work is an example of our "synergistic processing" philosophy combining these three technologies while taking advantage of their useful aspects. Aqueous solutions containing $\mathrm{NaNO}_{3}, \mathrm{Ca}\left(\mathrm{NO}_{3}\right)_{2} \cdot 4 \mathrm{H}_{2} \mathrm{O}$ and $\mathrm{KH}_{2} \mathrm{PO}_{4}$ (with or without urea) were irradiated in a household microwave oven for 5 min at 600 watts of power. The as-synthesized precursors were then simply stirred in water at room temperature for $1 \mathrm{~h}$ to obtain the nanowhiskers or powders of the desired calcium phosphate bioceramics.

\section{INTRODUCTION}

Calcium hydroxyapatite ${ }^{1}\left[\mathrm{HA}, \mathrm{Ca}_{10}\left(\mathrm{PO}_{4}\right)_{6}(\mathrm{OH})_{2}\right]$, the major inorganic phase of bones, is a member of the "apatite" family. However, biological apatites (e.g., enamel, dentin, and bone), differ from pure and synthetically produced calcium hydroxyapatite in stoichiometry, composition, crystallinity, and also in other physical and mechanical properties. ${ }^{1}$ Minor cations (e.g., $\mathrm{Na}^{+}, \mathrm{K}^{+}, \mathrm{Mg}^{2+}$, $\mathrm{Sr}^{2+}, \mathrm{Ba}^{2+}, \mathrm{Cu}^{2+}, \mathrm{Zn}^{2+}$, or $\mathrm{Fe}^{2+}$ ), and anions (e.g., $\mathrm{HCO}_{3}{ }^{-}, \mathrm{HPO}_{4}{ }^{2-}, \mathrm{Cl}^{-}$, and $\mathrm{F}^{-}$) are also associated with biological apatites. These can be considered ionic substituents in the apatite structure. The more resorbable $\beta$-tricalcium phosphate $\left[\beta-\mathrm{TCP}, \mathrm{Ca}_{3}\left(\mathrm{PO}_{4}\right)_{2}\right]$, when present in synthetic bone substitute materials, helps improving the resorption and bioactivity of the implanted bioceramics, and increase their ability in taking part in the in vivo bone remodeling processes.

HA or single-phase tricalcium phosphate (TCP) powders have generally been synthesized from aqueous solutions for use in bioceramic applications. It is known ${ }^{2}$ that calcium hydroxyapatite is the least soluble and the most stable calcium phosphate phase in aqueous solutions at $\mathrm{pH}$ values higher than 4.2. HA has been synthesized either in neutral or highly alkaline media ${ }^{3-6}$ to ensure the thermal stability of the formed phase after high-temperature (1100-1300 ${ }^{\circ} \mathrm{C}$ ) sintering. Synthesis of HA in neutral or slightly acidic media ${ }^{7}$ is known to be a more complicated and difficult task. The synthesis of biphasic mixtures of HA and TCP has also been achieved by aqueous coprecipitation. ${ }^{8}$ HA-TCP biphasic bioceramics, due to the higher in vivo solubility of beta-TCP,

\footnotetext{
a) Address all correspondence to this author.

e-mail: C_tas@hotmail.com

DOI: $10.1557 / J M R .2004 .0230$
}

display increased bioactivity as compared to more stable pure HA samples. ${ }^{9}$

This work utilizes a microwave-assisted "auto ignition" process to synthesize the aforementioned materials. ${ }^{10,11}$ The auto ignition synthesis has been referred to as combustion synthesis (CS) by Kingsley and Patil ${ }^{12}$ for the preparation of high-purity $\alpha$-alumina powders. We prefer to use the term auto ignition to distinguish it from "combustion synthesis" or "self-propagating high temperature synthesis," using mostly solid reactants. ${ }^{13,14}$ The process, which used urea $\left(\mathrm{H}_{2} \mathrm{NCONH}_{2}\right)$ as the fuel in a $\mathrm{Ca}\left(\mathrm{NO}_{3}\right)_{2} \cdot 4 \mathrm{H}_{2} \mathrm{O}$ and $\left(\mathrm{NH}_{4}\right)_{2} \mathrm{HPO}_{4}$ system of starting chemicals, was previously used to synthesize calcium phosphate powders. ${ }^{15} \mathrm{~A}$ variant procedure [citric acid and ethylene glycol, mixed with $\mathrm{Ca}\left(\mathrm{NO}_{3}\right)_{2} \cdot 4 \mathrm{H}_{2} \mathrm{O}$ and $\left.\mathrm{NH}_{4} \mathrm{H}_{2} \mathrm{PO}_{4}\right]$ based on the Pechini process ${ }^{16}$ was also shown to work well for the synthesis of calcium phosphate powders. ${ }^{17}$ However, both the combustion synthesis (or auto ignition) ${ }^{15}$ and Pechini-like process ${ }^{17}$ required high-temperature calcination steps (at 1000$1200{ }^{\circ} \mathrm{C}$ for prolonged periods) for the formation of the calcium phosphate phases (i.e., HA, TCP, or biphasic). This is where the advantage can be taken of molten salt synthesis. The molten salt synthesis technique, ${ }^{18}$ which uses a molten flux, was shown to form monodispersed whiskers of $\mathrm{HA}$ upon heating and cooling of a mixture of HA powders and $\mathrm{K}_{2} \mathrm{SO}_{4}$ from 1100 to $1200{ }^{\circ} \mathrm{C}$, followed by washing in water to remove the $\mathrm{K}_{2} \mathrm{SO}_{4}$ glass and expose the HA whiskers. ${ }^{19,20}$

The present communication reports the development of an extremely simple and rapid microwave-assisted, molten salt-combustion (auto ignition) synthesis hybrid procedure to manufacture nanowhiskers and nanopowders of HA, TCP, and HA-TCP biphasic bioceramics. The work is an example of our "synergistic processing" 
technique, which utilizes the useful features of the aforementioned processes.

\section{EXPERIMENTAL PROCEDURE}

Aqueous solutions containing dissolved $\mathrm{NaNO}_{3}$, $\mathrm{Ca}\left(\mathrm{NO}_{3}\right)_{2} \cdot 4 \mathrm{H}_{2} \mathrm{O}, \mathrm{KH}_{2} \mathrm{PO}_{4}$, concentrated $\mathrm{HNO}_{3}$, and urea (all reagent-grade, Fisher Chemicals, Fairlawn, NJ) were prepared in $10 \mathrm{ml}$ of deionized water in $30 \mathrm{ml}$-capacity Pyrex beakers, as shown in Table I. The first chemical added and dissolved in water was $\mathrm{NaNO}_{3}$, while the last one was urea. Small amounts of concentrated nitric acid were added for the sole purpose of dissolving back any colloidal calcium phosphates that might have formed following the addition of $\mathrm{Ca}$ - and phosphate-salts into the $\mathrm{NaNO}_{3}$ solution. Thus, for each case shown in Table I, clear-transparent solutions were obtained.

Small sample beakers were then placed onto $10 \times 10 \times$ $1 \mathrm{~cm}$ alumina insulating fiberboards and covered with an upside down $250 \mathrm{ml}$-capacity glass beaker. To proceed with the auto ignition-molten salt process, the abovementioned sample assemblies were placed into a household microwave (MW) oven (Sunbeam, max. power $600 \mathrm{~W}, 2.45 \mathrm{GHz}$, Boca Raton, FL) for only $5 \mathrm{~min}$. The MW oven was always operated at its maximum power setting. At the end of $5 \mathrm{~min}$ of $\mathrm{MW}$ heating within a well-ventilated fume hood, the sample beakers were taken out and their contents were let to cool down to room temperature (RT) in ambient atmosphere over the next 10-15 min. The substance in the sample beaker was then scraped off with a spatula, and directly placed (without grinding) into $500 \mathrm{~mL}$ of deionized water at RT $\left(22 \pm 1^{\circ} \mathrm{C}\right)$ and vigorously stirred for 1 hour. Formed suspension was filtered by using a vacuum-assisted Buechner funnel, and washed with $2 \mathrm{~L}$ of water, prior to drying the powders at $80{ }^{\circ} \mathrm{C}$ for 2 hours. Samples were characterized by powder $\mathrm{x}$-ray diffraction (XRD) (XDS 2000, Scintag, Sunnyvale, CA), Fourier transform infrared (FTIR) (Nicolet 550, Thermo-Nicolet, Woburn, MA), scanning electron microscopy (SEM) (Hitachi S-3500, Tokyo, Japan), FESEM (Hitachi S-4700), and ICP-AES (Thermo Jarrell Ash, Model 61E, Woburn, MA) analysis.

\section{RESULTS AND DISCUSSION}

Sample solutions placed into the MW oven first went through an initial stage of evaporation and boiling of

TABLE I. Sample preparation for HA, TCP, and HA-TCP biphasic samples.

\begin{tabular}{lcccccc}
\hline \hline & & \multicolumn{3}{c}{$15.69 \mathrm{M}$} \\
Sample & $\begin{array}{c}\mathrm{NaNO}_{3} \\
(\mathrm{~g})\end{array}$ & $\begin{array}{c}\mathrm{Ca}\left(\mathrm{NO}_{3}\right)_{2} \cdot 4 \mathrm{H}_{2} \mathrm{O} \\
(\mathrm{g})\end{array}$ & $\begin{array}{c}\mathrm{KH}_{2} \mathrm{PO}_{4} \\
(\mathrm{~g})\end{array}$ & $\begin{array}{c}\mathrm{HNO}_{3} \\
(\mathrm{ml})\end{array}$ & $\begin{array}{c}\mathrm{Urea} \\
(\mathrm{g})\end{array}$ & $\mathrm{Ca} / \mathrm{P}$ \\
\hline $\mathrm{HA}$ & 5.00 & 1.00 & 0.345 & 0.10 & 1.75 & 1.67 \\
TCP & 5.00 & 1.00 & 0.384 & 0.10 & $\ldots$ & 1.50 \\
Biphasic & 5.00 & 1.00 & 0.345 & 0.10 & 0.075 & 1.67 \\
\hline \hline
\end{tabular}
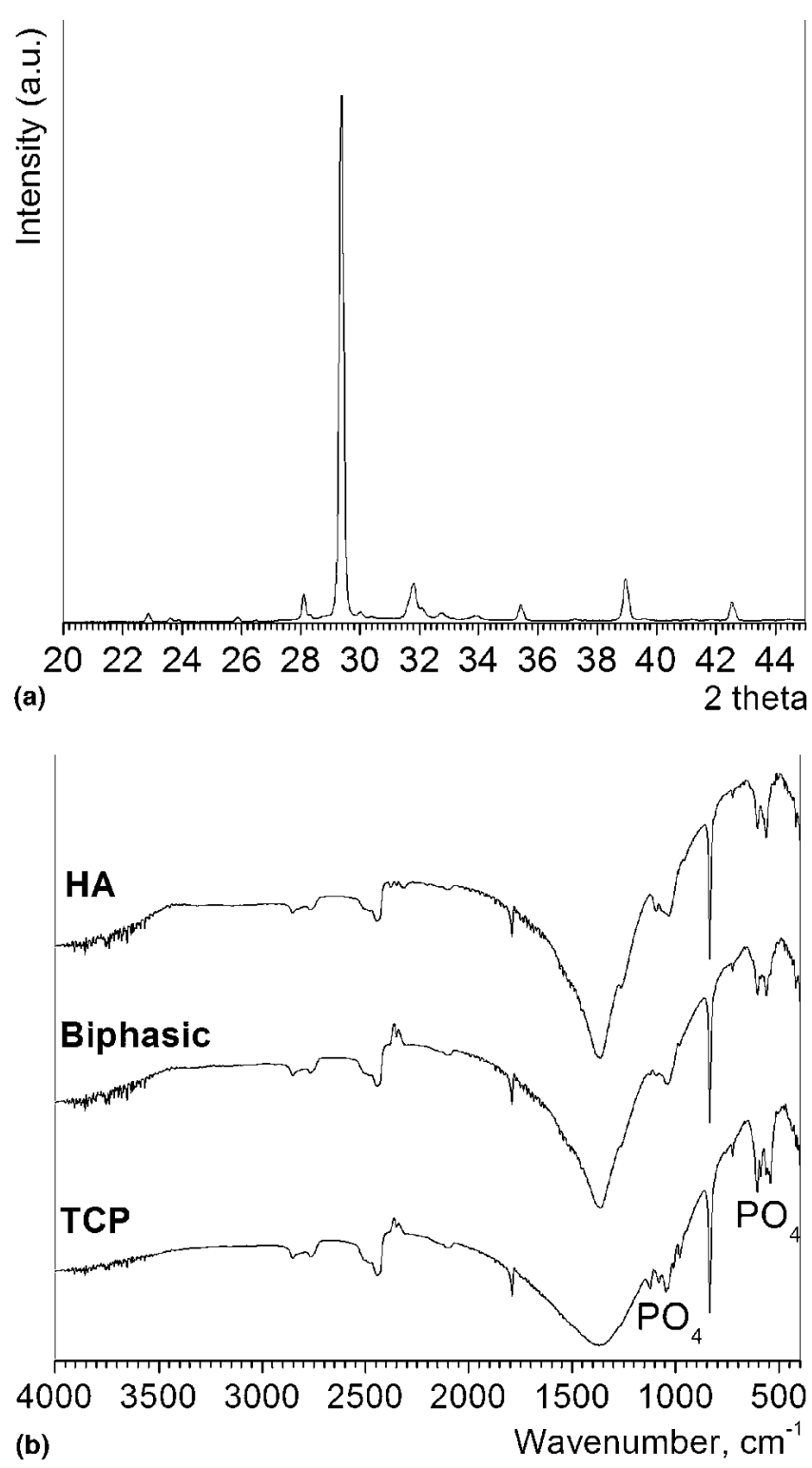

FIG. 1. XRD and FTIR data for the unwashed samples. (a) XRD data: single-phase $\mathrm{NaNO}_{3}$. (b) FTIR data: phosphate bands are present in otherwise a typical $\mathrm{NaNO}_{3}$ trace.

water. This obviously took place within the first minute. Urea is known ${ }^{21}$ to decompose into biuret $\left(\mathrm{H}_{2} \mathrm{~N}-\mathrm{CO}-\right.$ $\mathrm{NH}-\mathrm{CO}-\mathrm{NH}_{2}$, i.e., $\mathrm{C}_{2} \mathrm{H}_{5} \mathrm{~N}_{3} \mathrm{O}_{2}$ ), cyanuric acid ( $\mathrm{HCNO}$ ), and ammonia $\left(\mathrm{NH}_{3}\right)$ when it is heated to about $200{ }^{\circ} \mathrm{C}$. Biuret itself then decomposes when heated at temperatures $>300{ }^{\circ} \mathrm{C}$. Nitrate solutions, on the other hand, usually decompose at low temperatures with the evolution of gases, such as $\mathrm{NO}_{2}, \mathrm{NO}$, and $\mathrm{N}_{2} \mathrm{O}_{5}$. Moreover, we used $\mathrm{NaNO}_{3}$, which melts at $307{ }^{\circ} \mathrm{C},{ }^{22}$ at a high concentration in our liquid samples. It would have been possible to lower this salt melting temperature further if we were using mixtures of $\mathrm{NaNO}_{3}$ and $\mathrm{KNO}_{3} .{ }^{23-29}$ All the samples glowed red in the MW oven between the 90 and $240 \mathrm{~s}$ of heating time. In high urea solutions, intermittent 
sparks were also observed within that time period. This is the evidence of occurrence of combustion in this hybrid process. In the solutions containing urea, an exothermic reaction occurs which generates high temperatures leading to deformation of the Pyrex beakers. At the end of 5 min of MW irradiation, the recovered sample beakers only contained a liquid phase of slightly yellowish tint. $\mathrm{NaNO}_{3}$ did not evaporate and it formed a molten salt. This liquid phase solidified at RT within the following 4-5 min, by forming large dendritic crystals of $\mathrm{NaNO}_{3}$ on its surface.

Powder XRD data of all the unwashed samples (i.e., after $5 \mathrm{~min}$ of microwave heating, but without wash in water) only showed the presence of $\mathrm{NaNO}_{3}$ as the crystalline phase, as seen in Fig. 1(a). However, as expected, FTIR data of the unwashed precursors revealed the presence of characteristic phosphate infrared (IR) bands [labeled in Fig. 1(b)], as given in detail elsewhere. ${ }^{15,19}$

The relatively big chunks $(20-700 \mu \mathrm{m})$ common to all the unwashed samples, are shown in the SEM picture of Fig. 2(a). Scraping off of the reacted substance with a spatula from the inner walls of the reaction beakers led to that wide size distribution. Following the washing step, these chunks turned porous as seen in Fig. 2(b), upon the dissolution and removal of $\mathrm{NaNO}_{3} . \mathrm{pH}$ values of the washing solutions in situ raised to about 11.5-11.8 at the end of $1 \mathrm{~h}(t=60 \mathrm{~min})$ of stirring at RT. The $\mathrm{pH}$ value of the solutions at $t=0$ was around 10. Powders were further washed in a Buechner funnel filter unit until the effluent solution has reached a neutral $\mathrm{pH}$ value. Figures 2(c)-2(f) display the SEM morphology of the TCP, HA-TCP biphasic, and HA samples, respectively. TCP samples [Fig. 2(c)] mainly consisted of Whitlockite $(\beta$-TCP) rhombohedra, with only a small amount of whiskers. The solutions of TCP samples (with a $\mathrm{Ca} / \mathrm{P}$ molar ratio of 1.50 and solution $\mathrm{pH} \approx 0.9$ ) did not contain any urea, and there was almost no combustion observed during MW irradiation. The solutions containing urea $(\mathrm{pH} \approx 1.5)$ lead to the auto ignition-like process, and helped in increasing the temperature of the molten salt phase [Fig. 2(d)]. Growth of nanowhiskers is more readily facilitated within a molten salt of lower viscosity, otherwise equiaxed grains are observed, ${ }^{30}$ as depicted in Fig. 2(c). XRD and FTIR data for these samples are
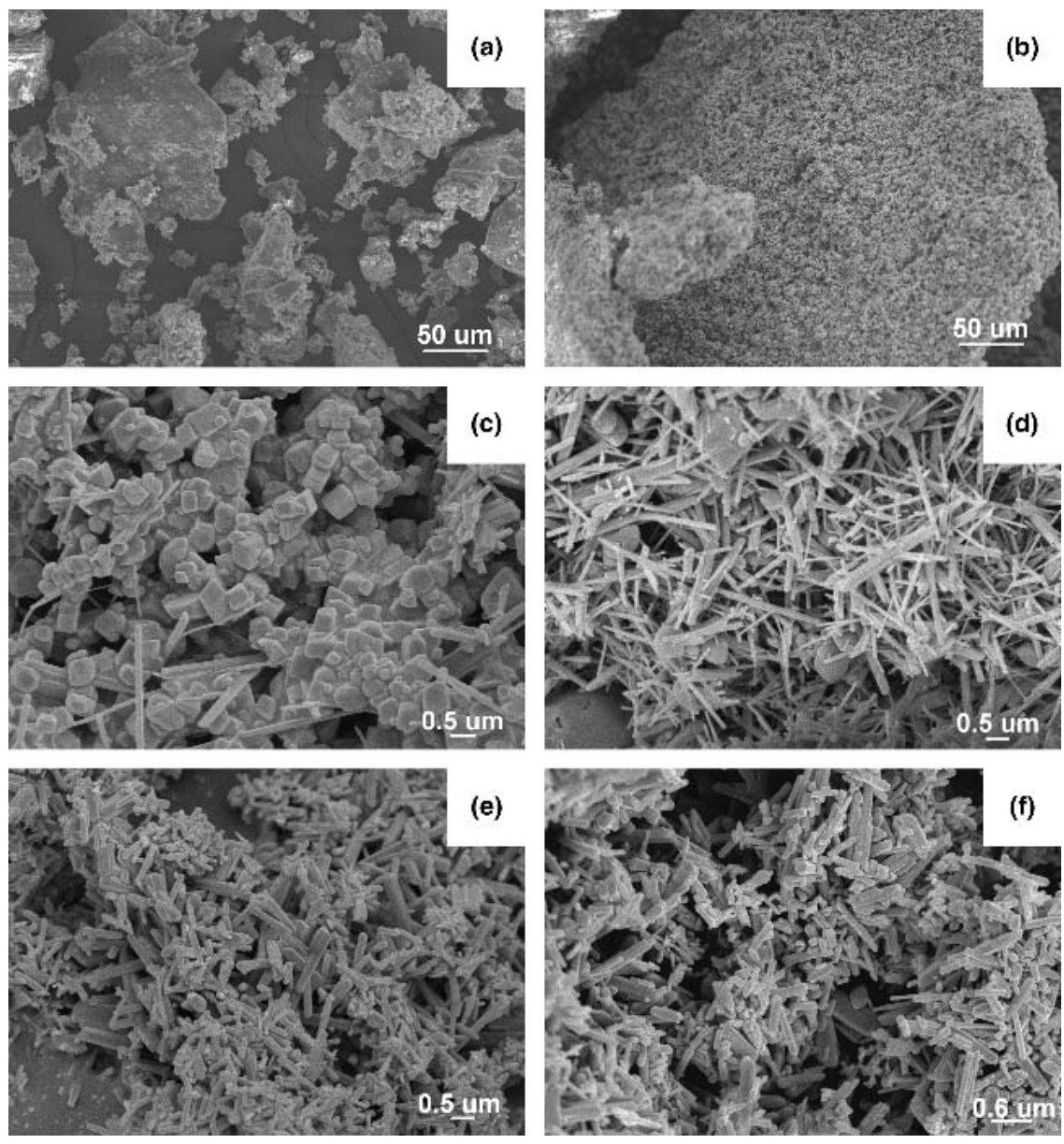

FIG. 2. SEM micrographs of calcium phosphate samples: (a) $\mathrm{NaNO}_{3}$-ctg precursors, low magnification, (b) after washing, low magnification, (c) TCP samples, (d) biphasic HA-TCP samples, and (e, f) HA samples. 
depicted in Fig. 3. Monodispersed nanowhiskers of HA obtained by this robust and simple process were about 1 $\mu \mathrm{m}$ long and $100 \mathrm{~nm}$ thick, as shown in Figs. 2(e) and 2(f). The biphasic samples [Figs. 2(d) and 3(a)] contained around $60 \%$ TCP and 40\% HA. The volume percentage of the HA phase can easily be adjusted by varying the urea content in the starting solutions, as shown in Fig. 4. Inductively coupled plasma analyses of the HA, TCP, and HA-TCP biphasic samples revealed that they contain around $1.5 \mathrm{wt} \% \mathrm{Na}$ and $250 \mathrm{ppm} \mathrm{K}$. In the case of HA samples, such ionic substitutions surely cause a deviation from the perfect stoichiometry of $\mathrm{Ca}_{10}\left(\mathrm{PO}_{4}\right)_{6}(\mathrm{OH})_{2}$. However, non-stoichiometry in an
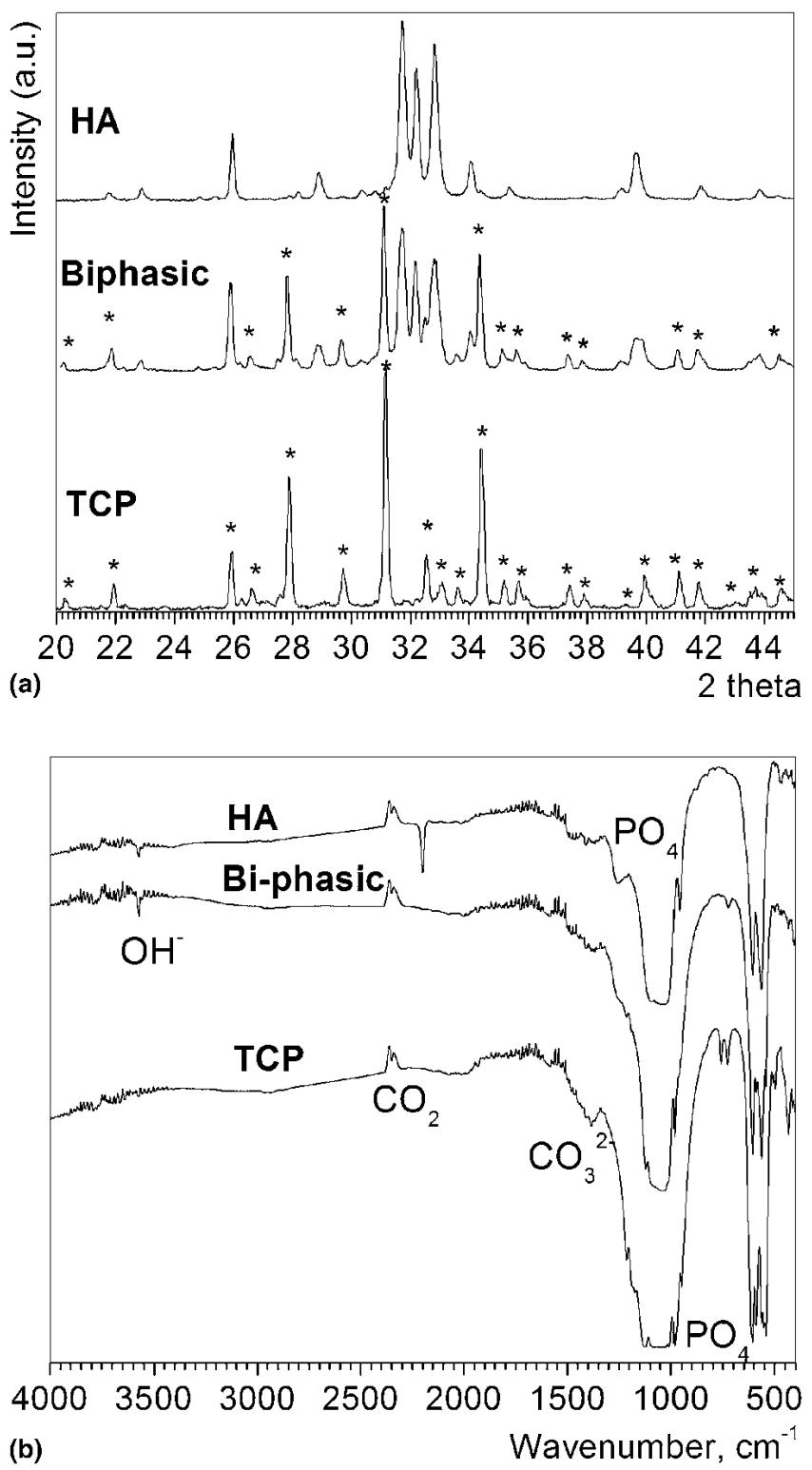

FIG. 3. XRD and FTIR data for calcium phosphate nanopowders and nanorods: (a) XRD traces, where $(*)$ denotes TCP peaks and (b) FTIR traces for TCP, biphasic, and HA samples.

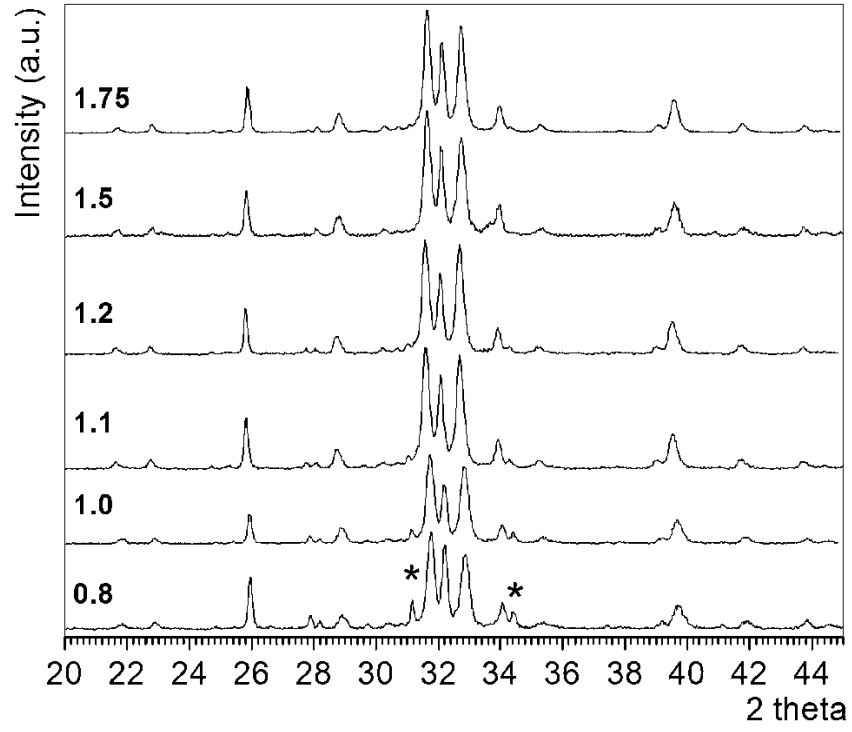

FIG. 4. XRD data showing the gradual elimination of the secondary phase of TCP with an increase in the weight of urea (in grams) during HA nanowhisker synthesis. TCP peaks are denoted by $(*)$.

apatitic calcium phosphate sample is perfectly acceptable if the aim is to produce a synthetic biomaterial which can resorb in vivo, and readily take part in the boneremodeling process. ${ }^{31}$ Human bones contain a total of 1.3 wt $\%$ of cations like $\mathrm{Na}^{+}, \mathrm{K}^{+}$, and $\mathrm{Mg}^{2+}$. . The process developed here yields bonelike calcium phosphate samples, as confirmed by the FTIR data of Fig. 3(b). Carbonate ion concentration in human bones amounts to a significant $5.8 \mathrm{wt} \%$ of the total weight. ${ }^{1}$ It is also a well known fact that either synthetic hydroxyapatites ${ }^{32}$ or human bones ${ }^{33}$ heated above $700{ }^{\circ} \mathrm{C}$ readily lose their carbonate ions.

An important part of the present work is the assistance of microwave heating. If we were to perform the combustion of our initial solutions (for the biphasic and HA samples) under conventional heating, for instance, in an electrical-resistance heated chamber furnace, the temperature distribution of the solution would be inhomogeneous. This is because the reaction beakers would have been heated by thermal conduction through a container wall, convection, and agitation. Since the synthesis of nanoparticles from their precursors in solutions consist of nucleation and particle growth, it is important that the particle growth is terminated. ${ }^{34}$ Those processes partly rely on the local temperature distribution within the solution. Any inhomogeneity in the temperature distribution would then cause broad distributions in particle size. MW irradiation should lead to homogeneous, i.e., molecular-level heating of the polar solution system, achieving automatic control of the above two processes required for the preparation of nanowhiskers or nanoparticles.

The liquid phase formed during this process by the 
molten $\mathrm{NaNO}_{3}$ dissolves all of the initially formed calcium phosphate precipitates. Such precipitates form during the initial boiling and evaporation of the excess water. Due to the presence of urea, an auto ignition process is initiated (as evidenced by the observation of intermittent sparks in the irradiated reaction beakers), and these in situ processes raise the extent of superheating in the molten-salt bath. Embryonic particles of calcium phosphate phases are formed through the nucleation and growth processes. As the molten ionic bath cools, while passing through its melting point down to room temperature, rapid crystallization occurs along the preferred growth axes of the ceramic phase. Calcium phosphate nanowhisker growth probably occurs during this rapid process, by a sequential "dissolution-crystallizationwhisker-growth" process.

Solubility of the specific calcium phosphates in molten $\mathrm{NaNO}_{3}$ (which is a function of temperature) has a significant role in the crystallization process to follow. The degree of superheating of the molten $\mathrm{NaNO}_{3}$ must also have a strong effect on the resultant aspect ratio of the formed whiskers. The morphology of the whiskers growing out of the cooling molten salt bath could be strongly dependent on soaking time at the peak temperature, as well as the cooling rate. Such issues further warrant follow-up studies, which we plan to report in due time.

\section{CONCLUSION}

A new microwave-assisted process has been developed for the synthesis of monodispersed nanowhiskers and nanopowders of Na- and carbonate-containing calcium phosphates. This new procedure is a hybrid of the urea-combustion (auto ignition) and molten salt synthesis techniques, and represents the philosophy of synergistic processing. The fluxing agent used was $\mathrm{NaNO}_{3}$. Urea was used as the fuel in the combustion part of this process. According to this synthesis route, $5 \mathrm{~min}$ of MW heating of aqueous solutions in a household MW oven at 600 watts, followed by $1 \mathrm{~h}$ of washing of the irradiated samples in water at RT was sufficient to form nanowhiskers. The 100-nm-thick HA nanowhiskers obtained had an aspect ratio of 10 . Procedure was successfully shown to yield single phase TCP, single phase HA, and biphasic HA-TCP samples. Nanowhiskers or powders produced in this study were chemically similar to human bones.

\section{ACKNOWLEDGMENT}

This work was partially supported by NSF DMII 0085100.

\section{REFERENCES}

1. L.L. Hench: Bioceramics: From concept to clinic. J. Am. Ceram. Soc. 74, 1478 (1991).
2. M. Jarcho, C.H. Bolen, M.B. Thomas, J. Bobock, J.F. Kay, and R.H. Doremus: Hydroxyapatite synthesis and characterization in dense polycrystalline form. J. Mater. Sci. 11, 2027 (1976).

3. M. Asada, Y. Miura, A. Osaka, K. Oukami, and S. Nakamura: Hydroxyapatite crystal growth on calcium hydroxyapatite ceramics. J. Mater. Sci. 23, 3202 (1988).

4. C.P.A.T. Klein, J.M.A. de Blieck-Hogerworst, J.G.C. Wolke, and K. de Groot: Studies of solubility of different calcium phosphate ceramic particles in vitro. Biomaterials 11, 509 (1990).

5. E. Ebrahimpour, M. Johnson, C.F. Richardson, and G.H. Nancollas: The characterization of HA precipitation. J. Colloid Interf. Sci. 159, 158 (1993).

6. A.C. Tas, F. Korkusuz, M. Timucin, and N. Akkas: An investigation of the chemical synthesis and high-temperature sintering behavior of calcium HA and TCP bioceramics. J. Mater. Sci. Mater. Med., 8, 91 (1997).

7. D. Bayraktar and A.C. Tas: Formation of Hydroxyapatite Precursors at $37{ }^{\circ} \mathrm{C}$ in urea- and enzyme urease-containing body fluids. J. Mater. Sci. Lett. 20, 401 (2001).

8. N. Kivrak and A.C. Tas: Synthesis of calcium hydroxyapatitetricalcium phosphate (HA-TCP) composite bioceramic powders and their sintering behavior. J. Am. Ceram. Soc. 81, 2245 (1998).

9. G. Daculsi, O. Laboux, O. Malard, and P. Weiss: Current state of the art of biphasic calcium phosphate bioceramics. J. Mater. Sci. Mater. Med., 14, 195 (2003).

10. R.H.G.A. Kiminami, M.R. Morelli, D.C. Folz, and D.E. Clark: Microwave synthesis of alumina powders. Am. Ceram. Soc. Bull. 79, 63 (2000).

11. R.H.G.A. Kiminami, M.R. Morelli, D.C. Folz, and D.E. Clark: Synthesis of $\mathrm{Al}_{2} \mathrm{O}_{3} / \mathrm{SiC}$ powders using microwave-induced combustion reaction. Mater. Trans. 42, 1661 (2001).

12. J.J. Kingsley and K.C. Patil: A novel combustion process for the synthesis of fine particle $\alpha$-alumina and related oxide materials. Mater. Lett. 6, 427 (1988).

13. S. Bhaduri, S.B. Bhaduri, and K.A. Prisbrey: Auto ignition synthesis of nanocrystalline of $\mathrm{MgAl}_{2} \mathrm{O}_{4}$ and related nanocomposites. J. Mater. Res. 14, 3571 (1999).

14. S.B. Bhaduri, S. Bhaduri, J.G. Huang, and W.R. Tinga: Auto ignition synthesis and microwave sintering of $\mathrm{CaO}$-stabilized nano $\mathrm{ZrO}_{2}$. Ceram. Eng. Sci. Proc. 20, 227 (1999).

15. A.C. Tas: Combustion synthesis of calcium phosphate bioceramic powders. J. Eur. Ceram. Soc. 20, 2389 (2000).

16. M.P. Pechini: Method of preparing lead and alkaline earth titanates and niobates and coating method using the same to form a capacitor. U.S. Patent No. 3330 697, 1967.

17. J. Pena and M. Vallet-Regi: Hydroxyapatite, tricalcium phosphate and biphasic materials prepared by a liquid mix technique. J. Eur. Ceram. Soc. 23, 1687 (2003).

18. R.H. Arendt: The molten salt synthesis of single magnetic domain $\mathrm{BaFe}_{12} \mathrm{O}_{19}$ and $\mathrm{SrFe}_{12} \mathrm{O}_{19}$ crystals. J. Solid State Chem. 8, 339 (1973).

19. A.C. Tas: Molten salt synthesis of calcium hydroxyapatite whiskers. J. Am. Ceram. Soc. 84, 295 (2001).

20. A.C. Tas: X-ray diffraction data for flux-grown calcium hydroxyapatite whiskers. Powder Diffr. 16, 102 (2001).

21. H. Varma, K.G. Warrier, and A.D. Damodaran: Metal nitrate-urea decomposition route for $\mathrm{Y}-\mathrm{Ba}-\mathrm{Cu}-\mathrm{O}$ powder. J. Am. Ceram. Soc. 73, 3103 (1990).

22. Handbook of Chemistry and Physics, 72nd edition, edited by D.R. Lide (CRC Press, Boca Raton, FL, 1992), pp. 4-99.

23. P. Afanasiev and C. Geantet: Effect of alkali metal cations on the properties of zirconia prepared in molten nitrates. Mater. Chem. Phys. 41, 18 (1995).

24. L. Saadi, R. Moussa, A. Samdi, and A. Mosset: Synthesis of mullite precursors in molten salts. Influence of the molten alkali nitrate and additives. J. Eur. Ceram. Soc. 19, 517 (1999). 
25. F. Bondioli, A.B. Corradi, C. Leonelli, and T. Manfredini: Nanosized $\mathrm{CeO}_{2}$ powders obtained by flux method. Mater. Res. Bull. 34, 2159 (1999).

26. L. Vayssieres, N. Beermann, S.E. Lindquist, and A. Hagfeldt: Controlled aqueous chemical growth of oriented threedimensional crystalline nanorod arrays: Application to iron (III) oxides. Chem. Mater. 13, 233 (2001).

27. A.B. Beleke, M. Mizuhata, and S. Deki: Diffuse reflectance FTIR spectroscopic study of interactions of $\alpha-\mathrm{Al}_{2} \mathrm{O}_{3} /$ molten $\mathrm{NaNO}_{3}$ coexisting systems. Phys. Chem. Chem. Phys. 5, 2089 (2003).

28. M. Park, C.L. Choi, W.T. Lim, M.C. Kim, J. Choi, and N.H. Heo: Molten-salt method for the synthesis of zeolitic materials I. Zeolite formation in alkaline molten-salt system. Microporous Mesoporous Mater. 37, 81 (2000).

29. P. Afanasiev: Molten salt synthesis of nitrate-exchanged magnesium and aluminum sodalites. Chem. Mater. 13, 459 (2001).
30. K.H. Yoon, Y.S. Cho, and D.H. Kang: Review: Molten salt synthesis of lead-based relaxors. J. Mater. Sci. 33, 2977 (1998).

31. D. Knaack, M.E.P. Goad, M. Aiolova, C. Rey, A. Tofighi, P. Chakravarthy, and D.D. Lee, Resorbable calcium phosphate bone substitute, J. Biomed. Mater. Res. 43, 399 (Appl. Biomater, 1998).

32. A.C. Tas: Synthesis of biomimetic Ca-hydroxyapatite powders at $37{ }^{\circ} \mathrm{C}$ in synthetic body fluids. Biomaterials. 21, 1429 (2000).

33. K.D. Rogers and P. Daniels: An x-ray diffraction study of the effects of heat treatment on bone mineral microstructure. Biomaterials 23, 2577 (2002).

34. H.B. Yin, T. Yamamoto, Y. Wada, and S. Yanagida: Large-scale and size-controlled synthesis of silver nanoparticles under microwave irradiation. Mater. Chem. Phys. 83, 66 (2004). 